\title{
The Prevalence and Determinants of Stunting among Children 6 - 59 Months of Age in One of the Sub-Counties in the Rwenzori Sub-Region, Western Uganda
}

\author{
Enos Mirembe Masereka1,2,3* ${ }^{1}$, Arthur Kiconco ${ }^{3}$, Edson Katsomyo², Clement Munguiko ${ }^{2,4}$ \\ ${ }^{1}$ Department of Nursing and Midwifery, School of Medicine, Kabale University, Kabale, Uganda \\ ${ }^{2}$ Department of Nursing and Midwifery, Mountains of the Moon University, Fort Portal, Uganda \\ ${ }^{3}$ Department of Public Health, Faculty of Health Sciences, Uganda Martyrs University, Kampala, Uganda \\ ${ }^{4}$ Department of Nursing, School of Health Sciences, Soroti University, Soroti, Uganda \\ Email:^mirembeenos@gmail.com,artkic@gmail.com,katsomyo@gmail.com,cclementmunguiko@yahoo.com
}

How to cite this paper: Masereka, E.M., Kiconco, A., Katsomyo, E. and Munguiko, C. (2020) The Prevalence and Determinants of Stunting among Children 6 - 59 Months of Age in One of the Sub-Counties in the Rwenzori Sub-Region, Western Uganda. Open Journal of Nursing, 10, 239-251.

https://doi.org/10.4236/ojn.2020.103016

Received: February 14, 2020

Accepted: March 21, 2020

Published: March 24, 2020

Copyright $\odot 2020$ by author(s) and Scientific Research Publishing Inc. This work is licensed under the Creative Commons Attribution International License (CC BY 4.0).

http://creativecommons.org/licenses/by/4.0/

(c) (i) Open Access

\section{Abstract}

Introduction: Despite being referred to as one of the country's "food baskets", $41 \%$ of children, 6 - 59 months of age in the Rwenzori sub-region, Western Uganda are stunted. Stunting is a form of chronic malnutrition in which children are short for their age. In this study, we established the prevalence and determinants of stunting in one of the sub-counties in this region. Methods: This was a cross-sectional descriptive study conducted in one of the sub-counties in the Rwenzori sub-region, Western Uganda from May $26^{\text {th }}$ to June $26^{\text {th }}, 2018$. A total of 372 mothers and their children were recruited using systematic sampling. Data was collected using a questionnaire. Stunting was determined by taking child's height or length and comparing it with child's age. A child whose height or length for age index was less than -2 Standard Deviations (SD) was considered stunted. We used descriptive statistics to understand characteristics of mothers and multivariable logistic regression model to obtain the determinants of stunting. Data was analyzed using SPSS version 20. Results: A total of 372 mothers and their children were included in this study; majority, 307 (83.0\%) of the children were 6 - 24 months old and nearly half, $167(44.9 \%)$ were stunted. We found that reserving food stock for use in the dry season $(\mathrm{aOR}=0.23, \mathrm{CI}=0.08-0.62, \mathrm{p}=$ $0.004)$, deworming children $(\mathrm{aOR}=0.32, \mathrm{CI}=0.18-0.54, \mathrm{p}=0.001)$ and the family earning at least 10,000 Ushs (2.7USD) at the end of the month $(\mathrm{aOR}=$ $0.36, \mathrm{CI}=0.22-0.58, \mathrm{P}=0.001)$ were associated with no stunting. Conclusions: We found a high prevalence of stunting among children 6 - 59 months 
of age. We recommend enforcing ownership of food granary by households especially during dry season, support to de-worming programs targeting children below five years of age and establishing community based income generating livelihood projects.

\section{Keywords}

Determinants, Stunting, Chronic Malnutrition, Children, Western, Uganda

\section{Introduction}

Worldwide, malnutrition is responsible for over 35\% of deaths among children 6 59 months of age [1]. Stunting, a form of chronic malnutrition and severe wasting, a form of acute malnutrition are the major contributors to childhood mortality [1]. More than $90 \%$ and $70 \%$ of the world's stunted and wasted children are found in Africa and Asia with a stunting prevalence of $36 \%$ in Africa and $27 \%$ in Asia [1]. Stunting is the impaired growth and development that children experience from poor nutrition, repeated infection and inadequate psychosocial stimulation [1]. Children are defined as stunted if their height-for-age index is more than two Standard Deviations (2 SD) below the WHO child growth standards median [1].

An analysis of African Demographic and Health Surveys (DHS) found that stunting was more prevalent in countries in the East and West Africa [2]. The prevalence of stunting was higher in Burundi at 57.7\% [2], Tanzania at 35.5\% [3] and Uganda at 29\% [4]. Although stunting seemed less prevalent in Uganda compared to Burundi and Tanzania, it largely remains a hidden problem due to challenges in its assessment, detection and reporting in communities [5]. There is an observed regional variation of stunting in Uganda that shows stunting as being more prevalent in the Rwenzori sub-region (41\%) compared to other sub-regions in Western Uganda [4]. Similarly, findings of earlier studies conducted in Rwenzori sub-region found the prevalence of $43.0 \%, 44.8 \%$ and $49.8 \%$ in Kabarole, Bundibugyo and Kasese districts respectively in 2010 [6]. These findings are similar to those of previously conducted Uganda Demographic and Health Surveys (UDHS) that found the prevalence rates of $42.8 \%$ in 1995, 40\% in 2002 , and $49.6 \%$ in 2006 in the Rwenzori sub-region [4] and as well as similar to the findings of studies conducted in other East African countries [7] [8]. A study that was conducted in central region of Tanzania and another national cross sectional study conducted in Burundi found that, about a half (49.7\%) and slightly more than half (53\%) of children during 6 - 59 months of age were stunted respectively. These studies associated stunting to young age of fathers and mothers of children, small babies for age at birth, being male child, mothers having no formal education, delivering at home, having more than 2 children below five years of age in a household and low wealth status [7] [8]. Earlier studies in west- 
ern Uganda have associated stunting to low wealth status as well, poor health of caregivers of children, residence located at a longer distance from the health unit and use of contaminated water [6].

Stunting impacts negatively on the cognitive and reproductive functions of both girls and boys [2]; Menarche for stunted girls occurs 1.3 years later, an indication of delay in sexual maturity. Stunted maternal height increases the risk of delivering Low Birth Weight (LBW) babies [2]. Pregnant women who are less than $145 \mathrm{~cm}$ in height have an increased risk of developing obstetric complications during childbirth and consequently increasing maternal morbidity and mortality [2]. The intellectual abilities for stunted boys and girls are low contributing to low school performance and poverty through impeding children's abilities to live productive lives [2]. Economic growth and human development require nonstunted populations who can learn new skills, think critically and contribute to the development of their communities [2]. The Rwenzori Sub-Region in Western Uganda has persistently had highest levels of childhood stunting despite being referred to as "the food basket" of the country [9]. Due to this we sought to establish the prevalence and determinants of stunting among children 6 - 59 months of age in one of the highly food productive rural sub-counties in the Rwenzori sub-region found in Western Uganda.

\section{Methods}

\subsection{Study Area, Population and Design}

This study employed a cross sectional descriptive study design. It was carried out from May $26^{\text {th }}$ to June $26^{\text {th }}, 2018$ in one rural sub-county in the Rwenzori sub-region found in Western Uganda. It was carried out among mothers and their children 6 - 59 months of age who were present at the household during data collection and had consented to participate. The study area had a total population of 10,617 people, about 1177 of whom are children 6 - 59 months of age [4]. The participants live along the foot hills of the Rwenzori ranges where variety of food crops are grown and animals are reared. Small scale businesses at the trading centres are one of the key income generating activities.

\subsection{Sample Size Determination and Participant Selection}

The sample size of this study was determined using the Leslie Kish survey sampling formula [10]. $\mathrm{Z}$ (the value from standard normal distribution) corresponding to desired confidence level of $95 \%$, was $1.96, \mathrm{p}$ (proportion of children 6 - 59 months of age who are stunted in the Rwenzori sub-region), estimated at $41 \%$ (0.41) [4], e (the desired level of precision), was set at 5\% (0.05) to arrive at $N$ (the actual sample size) of 372 respondents.

Prior to data collection, a household survey was conducted by Village Health Teams (VHTs) to register households with children 6 - 59 months of age in the entire sub-county. A total of 1136 children were found in 865 households and were registered as eligible, and were given numbers. We used systematic sam- 
pling and sampling interval of 3 to select children 6 - 59 months of age and their mothers. We moved to each registered household with eligible child and interviewed a child's mother or legal caregiver. When the child and the mother in a household declined to participate in the study, we moved to the next eligible household.

\subsection{Data Collection}

Data was collected using a questionnaire. To determine prevalence of stunting, data on child's height or length was obtained by measuring height or length using a height board. Length was measured for children young than 24 months while lying on a height board. Height was measured for older children when the child was standing. Questions on socio-demographic characteristics, diet, food security, hygiene and child determinants of stunting were asked. A Household was categorized as hygienic if the compound was clean, possessed a latrine and waste disposal pit. Child's de-worming status was confirmed from the child's health card, distances to the water source and nearby health facility were estimated by walking to respective destinations with a family member, a water source was categorized as safe if it was piped water, rain water, protected wells, bore halls and springs. Unprotected sources such as rivers and wells were considered unsafe.

\subsection{Data Analysis}

Data was analyzed using SPSS version 20. Participant demographic characteristics were summarized using descriptive statistics. The height for age index for every child 6 - 59 months of age was expressed as Standard Deviation (SD) unit or Z-score. A Child whose height for age Z-index (Z-score) was below -2 SD was categorized as stunted. We used multivariable logistic regression to establish determinants of stunting. Statistical significance was determined at $\mathrm{p} \leq 0.05$.

\subsection{Ethical Considerations and Protection of Study Participants}

Approval from a local ethics committee at the Faculty of Health Sciences (FHS) at Uganda Martyrs University was obtained. Written consent was sought from mothers and legal care takers of children assessed for stunting in this study.

\section{Results}

\subsection{Socio-Demographic Characteristics of Respondents}

In this study, a total of 372 mothers were interviewed and 372 children 6 - 59 months of age were assessed for stunting. Majority of the children 307 (83.0\%) were less than 2 years old. Most 297 (79.8\%) of the households had hygienic environments, with $319(85.8 \%)$ possessing a latrine. Most $216(58.2 \%)$ of the households were located more than $5 \mathrm{~km} \cdot \mathrm{s}$ away from the nearest health facility and 206 (55.4\%) of the households were located more than $1.5 \mathrm{~km} \cdot \mathrm{s}$ away from a water source. Most 229 (61.6\%) of the households fetched their water for domes- 
tic use from unsafe sources. Majority 371 (83.9\%) of the households used un-boiled and untreated water for drinking (Table 1).

\subsection{Prevalence of Stunting among Children 6 - 59 Months of Age in a Rural Sub-County in the Rwenzori Sub-Region in Western Uganda}

Nearly half 167 (44.9\%) of children below five years of age were stunted (Figure $1)$.

Table 1. Socio-demographic characteristics of mothers and their children 6 - 59 months of age in a rural sub-county in Rwenzori sub-region in Western Uganda.

\begin{tabular}{ccc}
\hline Variable & Frequency $(\mathbf{N}=\mathbf{3 7 2})$ & Percentage \\
\hline $\begin{array}{c}\text { Number of children in a home } \\
\leq 2 \text { years }\end{array}$ & 307 & 83.0 \\
$>2-5$ years & 65 & 17.0 \\
Distance to health unit & & \\
$\leq 5 \mathrm{~km} \cdot \mathrm{s}$ & 156 & 41.9 \\
$>5 \mathrm{~km} \cdot \mathrm{s}$ & 216 & 58.1 \\
Household hygiene & & \\
Hygienic & 297 & 79.8 \\
Not Hygienic & 75 & 20.2 \\
Availability of latrine & & \\
Available & 319 & 85.8 \\
Not available & 53 & 14.2 \\
Safe source & & 38.4 \\
Unsafe source & 143 & 61.6 \\
Source of water for drinking & 229 & \\
Distance to water source & & 44.6 \\
$\leq 1.5 \mathrm{~km} \cdot \mathrm{s}$ & 166 & 55.4 \\
$>1.5 \mathrm{~km} \cdot \mathrm{s}$ & 206 & 15.9 \\
Preparation of water for drinking & & 83.9 \\
Boil or use safeguard & 59 & \\
Does not boil or use safeguard & 371 & \\
\hline
\end{tabular}

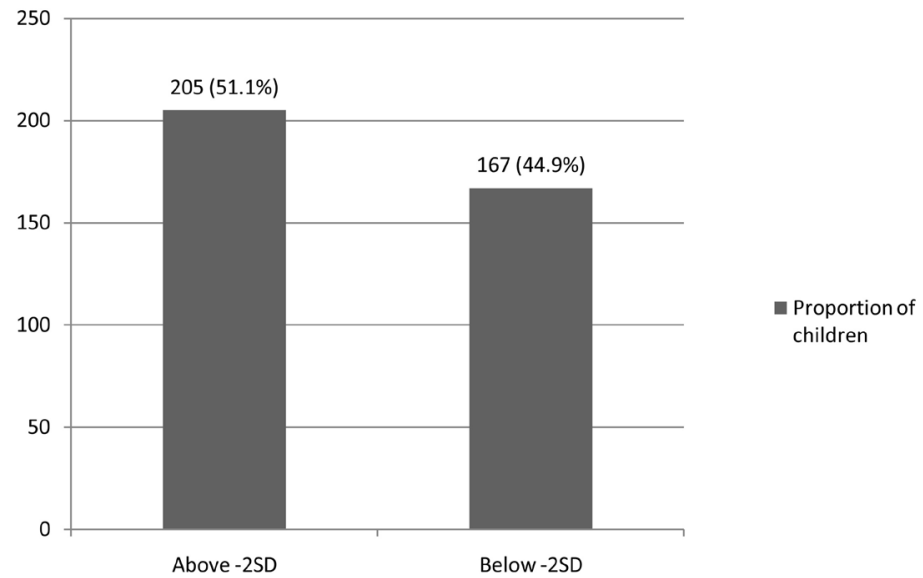

Figure 1. Level of stunting among children below five years of age in rural western Uganda. 


\subsection{Socio-Economic, Dietary and Child Determinants of Stunting in Children 6 - 59 Months of Age in a Rural Sub-County in Rwenzori Sub-Region in Western Uganda}

According to Table 2 below, reserving food stock for use in the dry season by the household $(\mathrm{aOR}=0.23, \mathrm{CI}=0.08-0.62, \mathrm{p}=0.004)$, deworming children in the household $(\mathrm{aOR}=0.32, \mathrm{CI}=0.18-0.54, \mathrm{p}=0.001)$ and the family earning at least 10,000 Ushs (2.7 USD) at the end of the month ( $\mathrm{aOR}=0.36, \mathrm{CI}=0.22$ $0.58, \mathrm{p}=0.001)$ were associated with no stunting in children $6-59$ months of age; Pre-lacteal feeding, type of feeding utensil, child feeding practices, household hygiene and child demographics (birth weight and birth order) did not show any association with stunting (Table 2).

Table 2. Socio-economic, dietary and child related determinants of stunting in children below 5 years of age in a rural sub-county in Western Uganda.

\begin{tabular}{|c|c|c|c|c|c|c|}
\hline \multirow{2}{*}{ Variable } & \multicolumn{6}{|c|}{ Nutrition status $(\mathrm{N}=372)$} \\
\hline & Stunted & Not stunted & Crude OR (95\% CI) & p-value & Adjusted OR (95\% CI) & $\mathrm{p}$-value \\
\hline \multicolumn{7}{|l|}{$\begin{array}{l}\text { Presence of food stock for use in dry } \\
\text { season }\end{array}$} \\
\hline Food stock & 6 & 27 & $0.23(0.09-0.58)$ & $\mathrm{P}=0.001$ & $0.23(0.08-0.62)$ & $\mathrm{P}=\mathbf{0 . 0 0 4}$ \\
\hline No food stock & 166 & 173 & & & & \\
\hline \multicolumn{7}{|l|}{$\begin{array}{l}\text { Feeds given before initiation of } \\
\text { breastfeeding }\end{array}$} \\
\hline Child was not given pre-lactation feeds & 42 & 67 & $0.64(0.41-1.01)$ & $\mathrm{P}=0.055$ & $1.94(0.55-1.61)$ & $\mathrm{P}=0.814$ \\
\hline Child was given pre- lactation feeds & 130 & 133 & & & & \\
\hline \multicolumn{7}{|l|}{ Child feeding 6 - 24 months } \\
\hline Child was exclusively breastfed & 4 & 1 & $4.59(0.21-5.29)$ & $\mathrm{P}=0.24$ & $0.13(0.01-1.32)$ & $\mathrm{P}=0.085$ \\
\hline Child was given complementary feeds & 171 & 196 & & & & \\
\hline \multicolumn{7}{|l|}{$\begin{array}{l}\text { Utensils used during complementary } \\
\text { feeding }\end{array}$} \\
\hline Cup & 142 & 178 & $0.59(0.32-1.06)$ & $\mathrm{P}=0.074$ & $0.61(0.30-1.22)$ & $\mathrm{P}=0.159$ \\
\hline Bottle & 30 & 22 & & & & \\
\hline \multicolumn{7}{|l|}{ Child's birth order } \\
\hline$\leq 4$ birth order & 113 & 114 & $1.45(0.95-2.20)$ & $\mathrm{P}=0.086$ & $1.23(0.76-2.01)$ & $\mathrm{P}=0.400$ \\
\hline$>4$ birth order & 59 & 86 & & & & \\
\hline \multicolumn{7}{|l|}{ Child's weight at birth } \\
\hline$\geq 2.5 \mathrm{~kg}$ & 149 & 185 & $0.53(0.27-1.04)$ & $\mathrm{P}=0.062$ & $0.51(0.23-1.13)$ & $\mathrm{P}=0.099$ \\
\hline $2.5 \mathrm{~kg}$ & 23 & 15 & & & & \\
\hline \multicolumn{7}{|l|}{ Child's deworming status } \\
\hline Up to date & 104 & 161 & $0.36(0.23-0.58)$ & $\mathrm{P}=0.001$ & $0.32(0.18-0.54)$ & $P=0.001$ \\
\hline Not up to date & 68 & 38 & & & & \\
\hline \multicolumn{7}{|l|}{ Family monthly income } \\
\hline Earns at least 10,000 Ushs & 73 & 144 & $0.28(0.18-0.43)$ & $\mathrm{P}=0.001$ & $0.36(0.22-0.58)$ & $P=0.001$ \\
\hline Does not earn & 99 & 55 & & & & \\
\hline \multicolumn{7}{|l|}{ Presence of latrine at home } \\
\hline Yes & 147 & 191 & $0.28(0.13-0.61)$ & $\mathrm{P}=0.001$ & $0.40(0.16-1.01)$ & $\mathrm{P}=0.052$ \\
\hline No & 25 & 9 & & & & \\
\hline
\end{tabular}




\section{Discussions}

In a rural sub-county in the Rwenzori sub-region in Western Uganda, $44.9 \%$ of children 6 - 59 months of age are stunted. These findings are similar to those of earlier studies conducted around the region [4] [6]. One wonders why there are constantly high trends of stunting in a region known to be one of the country's food baskets [9]. It is also hardly thought of that nutritional deficits among children can be a public health concern in such a region. Nutritional deficits if not corrected result in intergenerational malnutrition and affects the cognitive and reproductive functions of children impacting negatively on the quality of future citizens, as well as their economic productivity levels [2].

In this study, we found homesteads that reserve food stock for use in dry seasons less likely to have stunted children. Homesteads without food reserved for dry season were more likely to survive on nutrient deficient foods. Children being a vulnerable group are more likely to be affected compared to older family members. Lack of or inadequate food in a household leads to restricted child growth and development. Availability of nutrient dense foods can be ensured by storing food at home throughout seasons, a practice that is ceasing to exist in many Ugandan households [11] [12] [13]. Similarly homesteads that were earning at least 10,000 Ugandan shillings (2.7 USD) at the end of the month were less likely to have stunted children. Food security in a household is defined by either physical presence of food or money to buy food or both [14]. Wealth status of a household determines whether the family is in position to buy variety of food stuffs to meet nutritional requirements for enhanced child growth and development [14] [15].

In this study, children whose deworming status was up-to-date were less likely to be stunted. Conversely, children who were not fully dewormed were more likely to be stunted. Studies have established the association between stunting and helmintic infestations. Infestations impair the body's ability to absorb and utilize food nutrients. Deworming decreases or eliminates the population of helminths (worms) in the child's gastrointestinal tract and this reduces the competition for nutrients, ensures availability of nutrients and facilities appropriate child growth and development [16].

\section{Conclusion}

We found a high prevalence of stunting among children 6 - 59 months of age. Like other studies, we found that occurrence of stunting in children 6 - 59 months of age is determined by socio-economic, dietary and child factors, especially food insecurity, low household income and failure to deworm children. We recommend enforcing ownership of food granary by households, especially during dry season, support to deworming programs targeting children below five years of age and establishing community based income generating livelihood projects. 


\section{Study Limitation}

The study relied on responses from mothers and some of these might have been affected by recall bias. We endeavored to clearly articulate the questions to ensure that the mothers responded accurately.

\section{Declarations}

\section{Ethical Approval and Consent to Participate}

Approval was sought from a local ethics committee at the Faculty of Health Sciences at Uganda Martyrs University. Written consent was sought from mothers and legal care takers of children assessed for stunting in this study.

\section{Availability of Data and Materials}

All data and materials for this study shall be availed whenever requested by editorial team and other users. The data set can be accessed by sending a request to mirembeenos@gmail.com.

\section{Acknowledgements}

The authors of this study would like to thank the leadership of Ntoroko District Local Government for allowing this study to be conducted in Ntoroko District, Rwenzori SuB-Region in Western Uganda; we also thank all women and their children who participated in this study.

\section{Authors' Contribution}

EMM and AK conceived the study; EMM \& EK collected and analyzed data; EMM and CM wrote the manuscript.

\section{Conflicts of Interest}

The authors declare no competing interests in this study.

\section{References}

[1] World Health Organization (2019) Levels and Trends in Child Malnutrition: Key Findings of the 2019 Edition (No. WHO/NMH/NHD/19.20).

https://apps.who.int/iris/bitstream/handle/10665/331097/WHO-NMH-NHD-19.20eng.pdf

[2] Akombi, B.J., Agho, K.E., Hall, J.J., Merom, D., Astell-Burt, T. and Renzaho, A.M. (2017) Stunting and Severe Stunting among Children Under-5 Years in Nigeria: A Multilevel Analysis. BMC Pediatrics, 17, Article No. 15. https://link.springer.com/article/10.1186/s12887-016-0770-z https://doi.org/10.1186/s12887-016-0770-Z

[3] Chirande, L., Charwe, D., Mbwana, H., Victor, R., Kimboka, S., Issaka, A.I. and Agho, K.E. (2015) Determinants of Stunting and Severe Stunting among Under-Fives in Tanzania: Evidence from the 2010 Cross-Sectional Household Survey. BMC Pediatrics, 15, Article No. 165. https://doi.org/10.1186/s12887-015-0482-9 https://link.springer.com/article/10.1186/s12887-015-0482-9 
[4] UDHS (2016) Uganda Demographic Health Survey, 2016. https://dhsprogram.com/pubs/pdf/FR333/FR333.pdf

[5] UNAP (2011) Uganda Nutrition Action Plan (UNAP) 2011-2016. http://www.health.go.ug/docs/UNAP_11_16.pdf

[6] Biondi, D., Kipp, W., Jhangri, G.S., Alibhai, A., Rubaale, T. and Saunders, L.D. (2010) Risk Factors and Trends in Childhood Stunting in a District in Western Uganda. Journal of Tropical Pediatrics, 57, 24-33.

https://academic.oup.com/tropej/article/57/1/24/1725289 https://doi.org/10.1093/tropej/fmq043

[7] Semali, I.A., Tengia-Kessy, A., Mmbaga, E.J. and Leyna, G. (2015) Prevalence and Determinants of Stunting in Under-Five Children in Central Tanzania: Remaining Threats to Achieving Millenium Development Goal 4. BMC Public Health, 15, Article No. 1153. https://doi.org/10.1186/s12889-015-2507-6 https://bmcpublichealth.biomedcentral.com/articles/10.1186/s12889-015-2507-6

[8] Nkurunziza, S., Meessen, B. and Korachais, C. (2017) Determinants of Stunting \& Severe Stunting among Burundian Children Aged 6-23 Months: Evidence from a National Cross-Sectional Household Survey, 2014. BMC Pediatrics, 17, Article No. 176. https://link.springer.com/article/10.1186/s12887-017-0929-2 https://doi.org/10.1186/s12887-017-0929-2

[9] Kikafunda, J.K., Agaba, E. and Bambuna, A. (2014) Malnutrition amidst Plenty; an Assessment of Factors Responsible for Persistent High Levels of Childhood Stunting in Food Secure Western Uganda. African Journal of Food, Agriculture, Nutrition and Development, 14, 9288-9313.

https://www.ajol.info/index.php/ajfand/article/view/107905

[10] Kish, L. (2004) Statistical Design for Research (Vol. 83). John Wiley \& Sons, Hoboken. https://books.google.co.ug/books?hl=en\&lr=\&id=ZM4lw

[11] McKinney, P. (2009) Comprehensive Food Security and Vulnerability Assessment: Uganda. VAM Food Security Analysis. WFP, Rome.

https://reliefweb.int/report/uganda/uganda-comprehensive-food-security-and-vuln erability-analysis-apr-2009

[12] Hien, N.N. and Kam, S. (2008) Nutritional Status and the Characteristics Related to Malnutrition in Children under Five Years of Age in Nghean, Vietnam. Journal of Preventive Medicine and Public Health, 41, 232-240.

https://pdfs.semanticscholar.org/d991/98b5943d054348317ee5d0e555ca02a1adc7.pd $\underline{\mathrm{f}}$

https://doi.org/10.3961/jpmph.2008.41.4.232

[13] MOH (2007) Infant and Young Child Feeding (IYCF) Guidelines for Uganda. Ministry of Health, Kampala.

http://www.iycn.org/files/UgandaIYCFpolicyguidelinesfinaldraftMay2007.pdf

[14] Keino, S., Plasqui, G., Ettyang, G. and van den Borne, B. (2014) Determinants of Stunting and Overweight among Young Children and Adolescents in Sub-Saharan Africa. Food and Nutrition Bulletin, 35, 167-178.

https://journals.sagepub.com/doi/abs/10.1177/156482651403500203 https://doi.org/10.1177/156482651403500203

[15] Aheto, J.M.K., Keegan, T.J., Taylor, B.M. and Diggle, P.J. (2015) Childhood Malnutrition and Its Determinants among Under-Five Children in Ghana. Paediatric and Perinatal Epidemiology, 29, 552-561. https://doi.org/10.1111/ppe.12222 https://onlinelibrary.wiley.com/doi/abs/10.1111/ppe.12222

[16] Tyoalumun, K., Abubakar, S. and Christopher, N. (2016) Prevalence of Intestinal 
Parasitic Infections and Their Association with Nutritional Status of Rural and Urban Pre-School Children in Benue State, Nigeria. International Journal of MCH and AIDS, 5, 146. https://www.ncbi.nlm.nih.gov/pmc/articles/PMC5187646 


\section{Questions that Were Asked}

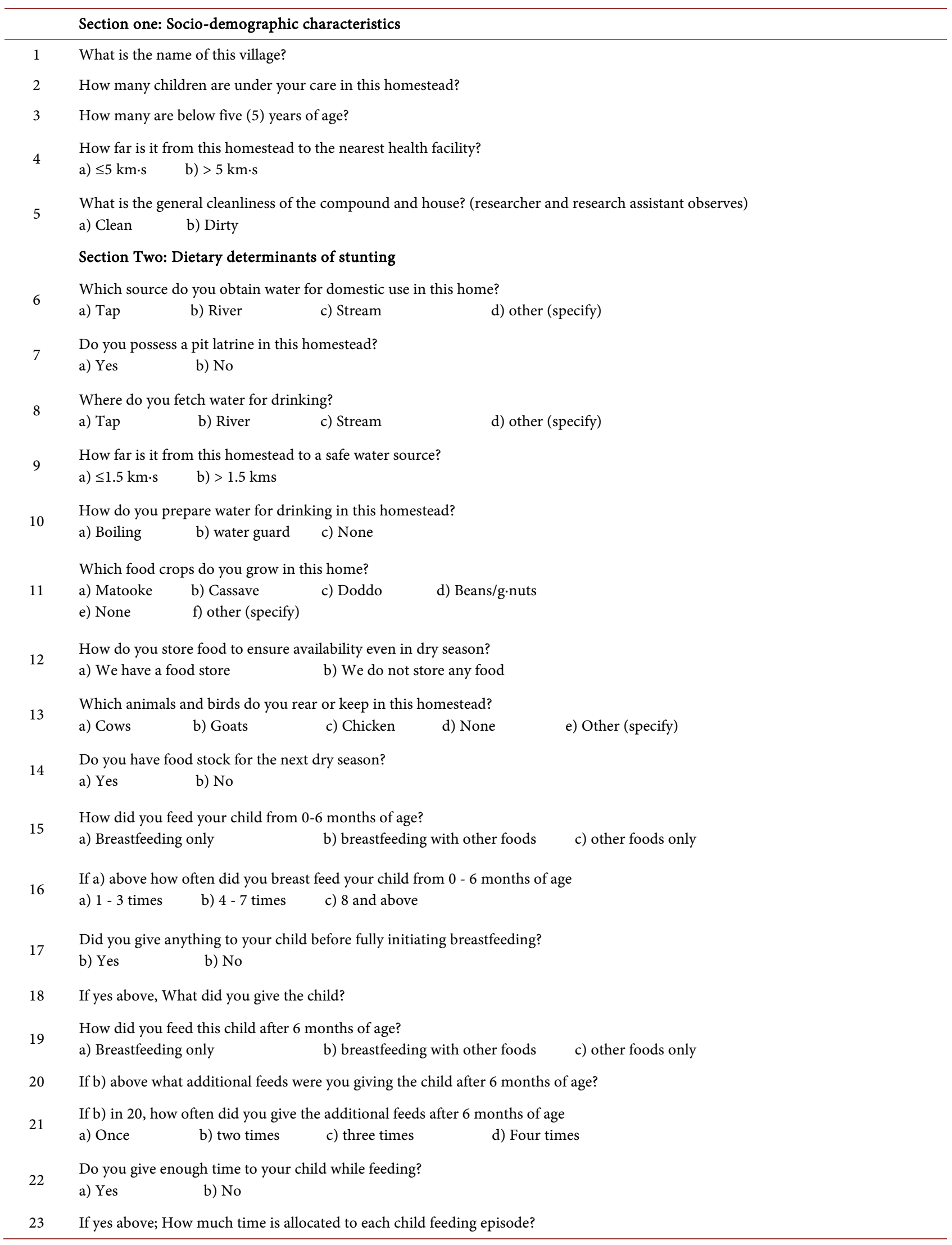




\section{Continued}

24
a) A bottle with teat
b) a cup
c) other (specify)

25 At what age did you wean your child?

If the child is below 1 year of age; is the child's immunization status up to date? (researcher and research assistant confirms from the

26 child's immunization card)
a) Yes
b) $\mathrm{No}$

If the child is above 1 year of age, has the child been de-wormed in the last 3 months?
a) Yes
b) $\mathrm{No}$

28

If the child is above 1 year of age, is his/her vitamin A supplementation up to date?
a) Yes
b) $\mathrm{No}$

\section{Section Three: Maternal determinants of stunting}

29
a) Yes
b) $\mathrm{No}$

What is your highest level of education?
a) None
b) Primary
c) $\mathrm{S} 1-4$
d) S5-6d tertiary
e) University

What do you do to earn a living a living?
a) Peasantry
b) Business
c) Office work
d) others (specify)
e) none

32 How much do you earn per month?

33 How old were you when you gave birth to this child?

34 Did you eat adequately the time you were pregnant?
a) Yes
b) No

35

If yes above, what were you feeding on?

In this homestead, do you believe in the following?

a) Extracting false teeth for children

b) Giving the new born water before breastfeeding starts

c) Other(s)

\section{Section Four: Child determinants of stunting}

What is the sex of your child?

38 How old is your child now?

39 What was the weight of the child at birth?

40 How old is this child?

41 What is the birth order of the child?

42 What is the birth interval between the child and older child?

43 Has your child suffered any of the following illnesses in the last 3 months?
a) On and off fevers $>1$ week
b) Diarrhea
c) Persistent cough $>3$ weeks
d) Other

\section{Child's anthropometry}

Height/length Weight

MUAC

The End

Thank you so much 


\section{List of Abbreviations}

DHS Demographic and Health Survey

FHS Faculty of Health Sciences

IYCF Infant and Young Child Feeding

LBW Low Birth Weight

SD Standard Deviation

SDHR Support to Skills Development for Human Resources

UDHS Uganda Demographic and Health Survey

UNAP Uganda Nutrition Action Plan

UNICEF United Nations Children's Emergency Fund

VHT Village Health Teams

WASH Water, Sanitation and Hygiene 